\title{
Common circuit defect of excitatory-inhibitory balance in mouse models of autism
}

\author{
Nadine Gogolla • Jocelyn J. LeBlanc • \\ Kathleen B. Quast • Thomas C. Südhof • \\ Michela Fagiolini • Takao K. Hensch
}

Received: 22 May 2009 / Accepted: 31 May 2009 /Published online: 11 July 2009

(C) Springer Science + Business Media, LLC 2009

\begin{abstract}
One unifying explanation for the complexity of Autism Spectrum Disorders (ASD) may lie in the disruption of excitatory/inhibitory (E/I) circuit balance during critical periods of development. We examined whether Parvalbumin (PV)-positive inhibitory neurons, which normally drive experience-dependent circuit refinement (Hensch Nat Rev Neurosci 6:877-888, 1), are disrupted across heterogeneous ASD mouse models. We performed a meta-analysis of PV expression in previously published ASD mouse models and analyzed two additional models, reflecting an embryonic chemical insult (prenatal valproate, VPA) or single-gene mutation identified in human patients (Neuroligin-3, NL-3 R451C). PV-cells were reduced in the neocortex across multiple ASD mouse models. In striking contrast to controls, both VPA and NL-3 mouse models exhibited an asymmetric
\end{abstract}

Gogolla, LeBlanc and Quast have equal contribution to this article

Electronic supplementary material The online version of this article (doi:10.1007/s11689-009-9023-x) contains supplementary material, which is available to authorized users.

N. Gogolla $\cdot$ K. B. Quast • T. K. Hensch

Center for Brain Science, Dept. Molecular \& Cellular Biology,

Harvard University,

52 Oxford St.,

Cambridge, MA 02138, USA

J. J. LeBlanc $\cdot$ K. B. Quast • M. Fagiolini $(\bowtie) \cdot$ T. K. Hensch $(\square)$

FM Kirby Neurobiology Center, Dept. Neurology,

Children's Hospital Boston, Harvard Medical School,

300 Longwood Ave,

Boston, MA 02115, USA

e-mail: michela.fagiolini@childrens.harvard.edu

e-mail: hensch@mcb.harvard.edu

T. C. Südhof

HHMI, Stanford School of Medicine,

1050 Arastradero Road (B249F),

Palo Alto, CA 94304, USA
PV-cell reduction across hemispheres in parietal and occipital cortices (but not the underlying area CA1). ASD mouse models may share a PV-circuit disruption, providing new insight into circuit development and potential prevention by treatment of autism.

Keywords Parvalbumin · VPA · Neuroligin · GABA

A severe neurobehavioral syndrome with a heterogeneous phenotype, autism spectrum disorders (ASD) are among the most heritable neurodevelopmental disorders of early childhood with an incidence as high as one child in 166. ASD is primarily a genetic disorder of prenatal and early postnatal brain development involving multiple risk genes, disrupted epigenetic pathways and possible environmental insults [2]. At present, there is no wholly effective treatment nor is it understood which biological pathways are specifically disrupted in individuals with autism. The diagnostic indicators of autism are core behavioral symptoms, rather than definitive neuropathological markers. Autistic children exhibit impaired language, abnormal social interactions and repetitive behaviors. One third of ASD patients have seizures and evidence of altered inhibition in the brain [3].

One unifying explanation for the complexity of ASD may lie in the disruption of excitatory/ inhibitory (E/I) circuit balance during critical periods of development [4-6]. Neuronal circuits are refined by extraordinary levels of plasticity during sensitive periods in early development, which are diminished in adulthood. It is during these "critical periods" that single neurons acquire multiple functional properties through an experience-dependent maturation. Recent findings have revealed that E/I circuit dynamics can dictate the normal timing of critical periods in brain development [1]. Gene-targeted deletion of a 
GABA-synthetic enzyme (GAD65 KO) in mice delays plasticity onset within the visual cortex indefinitely [7], which can be rescued at any age with benzodiazepines [8].

Detailed local circuit analysis in vivo has further identified a single GABAergic cell type - the Parvalbumin (PV)positive basket cell (Fig. 1) - as the key player for critical period plasticity [9-11]. The calcium-binding protein PV marks the largest class of inhibitory interneuron in the cortex and makes up $\sim 40 \%$ of the GABA cell population [12]. They are born in the medial ganglionic eminence (MGE) on embryonic day E13.5 [13] and can later be found throughout the brain, including hippocampus, thalamus and cortex.

In neocortex, the two primary types of PV-cell are axon initial segment-targeting chandelier cells and soma-targeting large basket cells. The latter have a large, round soma with several prominent radial dendrites. PV expression begins near postnatal day P12 in layer 5 and matures in an inside-out laminar progression by around P21 in visual cortex and somewhat earlier in somatosensory and other cortical regions $[12,14]$. With age, PV-cells become preferentially enwrapped in chondroitin sulphate proteoglycans that form a perineuronal net, which may buffer the ionic environment surrounding these cells [15] or act to limit growth and sprouting of impinging thalamic axon terminals [16]. Interestingly, removal of these nets can reactivate critical period plasticity in adult animals [17].

The mouse model system provides a method to experimentally test whether postnatal neurodevelopmental disorders of human cognition involve dysfunction of such critically timed activity-dependent processes. Mouse models of ASD have been developed that reflect genetic alterations associated with autism [18]. Some are based on monogenic aberrations (Neuroligin-3, Neuroligin-4, MeCP2, TSC1/2, FMR1, ubiquitin protein ligase $3 \mathrm{~A}(\mathrm{Ube} 3 \mathrm{~A}))$ that underlie syndromes associated with autistic-like behavior. Other mutant lines are relevant to loci for autism susceptibility, identified by association or linkage in human populations. Advances have included the evaluation of mouse models with behavioral assays designed to reflect disease symptoms, including impaired social interaction, communication deficits and repetitive behaviors, and symptom onset during the neonatal period.

A meta-analysis of previously published reports reveals that PV-cells are consistently reduced in the neocortex of multiple mouse models of ASD (Table 1). Such a shared circuit defect from heterogeneous genetic origins may further our understanding of the complex etiology of ASD and offers novel targets for therapeutic intervention. We therefore examined a representative embryonic insult and single-gene mutation model in greater detail from a PV-cell perspective.

Global genetic perturbations are produced by prenatal or neonatal environmental challenges, including early exposure to the HDAC inhibitor valproic acid (VPA) or inflammatory agents that have been suggested as autism risk factors by clinical surveys. A robust model has previously been developed in rats based on the fact that treatment of epilepsy or bipolar disorder in pregnant women around 20-24 days post-conception with the drug VPA is linked to an increased incidence of ASD in their children [19-21]. The physically healthy offspring of pregnant rats treated with a single dose of VPA at an equivalent gestational time point recapitulate the human ASD phenotype [22, 23]. Related VPA mouse models have been attempted, but most involve postnatal VPA treatment not consistent with human studies [24, 25]. One group used a slightly higher dose at a later time point, but they did not evaluate behaviors implicated in autism [24].
Fig. 1 Specific GABA circuits (large basket PV-cells) trigger a developmental critical period. $\mathrm{PV}$, parvalbumin; CR, calretinin; SOM, somatostatin; CCK, cholecystokinin; a1-6, GABA-A receptor a-subunit

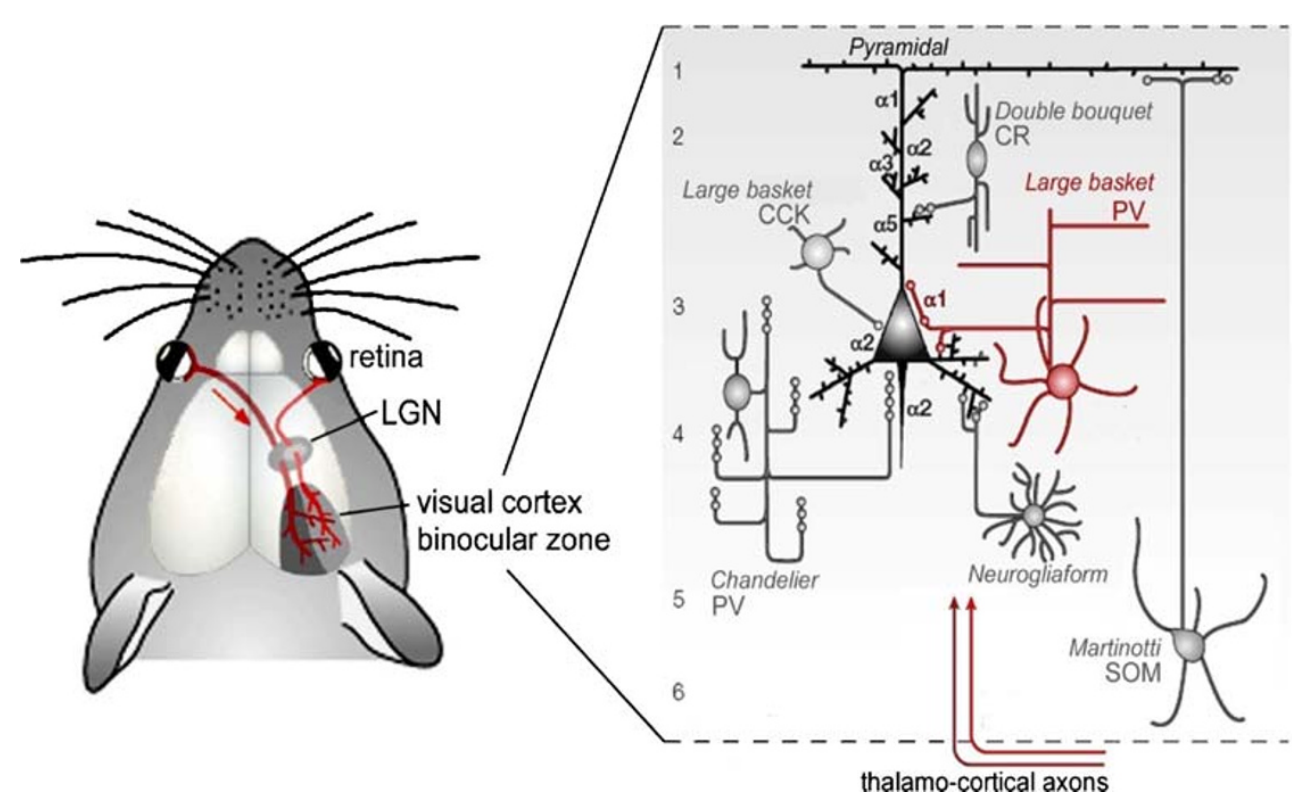


Table 1 PV-cell deficits across ASD mouse models

\begin{tabular}{llll}
\hline Gene/Condition & Region & Age & Reference \\
\hline FMRP & somatosensory cortex & $\mathrm{P} 365$ & {$[94]$} \\
$M e C P 2$ & somatosensory cortex & $\mathrm{P} 14$ & {$[95]$} \\
$C A P S 2$ & motor cortex & $\mathrm{P} 17$ & {$[96]$} \\
$u P A R$ & anterior cingulate cortex parietal cortex & $>\mathrm{P} 90$ & {$[97]$} \\
$N L-3$ & somatosensory cortex & $>\mathrm{P} 60$ & this study \\
VPA & parietal cortex & $>\mathrm{P} 60$ & this study \\
prenatal immune challenge & medial prefrontal cortex & adult & {$[98]$} \\
$N P N 2$ & hippocampus area CA3/CA1 & $>\mathrm{P} 60$ & {$[99]$} \\
$E n-2$ & hippocampus area CA3 & $\mathrm{P} 150$ & {$[100]$} \\
\hline
\end{tabular}

We translated the well-established rat model into mice by using the same dose at an equivalent injection time point and evaluated behavior of the offspring [26, 27]. Five out of nine VPA-injected pregnant females $(500 \mathrm{mg} / \mathrm{kg}$, i.p.) gave birth to viable litters, and of these, two litters included some mice with minor skeletal defects like bent tails and fused fingers. We concluded that this dose was appropriate because it was strong enough to have a teratogenic effect, but not too strong to cause gross impairments. We then compared PV-cell anomalies in the brain by immunostaining of VPA-treated mice and a representative single-gene mutant of Neuroligin-3 (NL-3 R451C) reported to exhibit autistic features [28] concomitant with enhanced cortical inhibitory synapse function [6]. Note that an independently generated R451C mutant mouse line revealed a different behavioral phenotype, but was not characterized for expression of mutant NL-3 and its electrophysiological consequences [29], making it unclear how similar the line is to the original R451C mutant mice.

\section{Common disruption of parvalbumin-positive GABA circuits in ASD models}

To determine whether our VPA mouse model shares a similar disruption of inhibitory circuits with other mouse models of ASD, we analyzed the distribution of PV-positive interneurons in the brains of adult mice ( $>$ P60). In contrast to the even distribution across the neocortex of control animals, several areas in the neocortex of VPA-exposed mice entirely lacked PV-cells or had substantially reduced PV-cell numbers especially in the upper layers (Fig. 2a). These zones of sparse or absent PV-cell labeling ("PVempty zones") spanned several hundred micrometers in the rostro-caudal extent and did not match any single modality but rather partially affected several functional compartments, such as the primary somatosensory and secondary visual cortices. PV-empty zones were surrounded by areas that displayed normal PV-cell densities.

The precise location and extent of PV-empty zones were slightly variable among littermates that shared concomitant prenatal VPA exposure, including a small subset that did not exhibit any noticeable abnormality. However, the majority of VPA-treated mice shared a common PV-empty zone in a region around the caudal part of primary somatosensory cortex. We therefore decided to analyze this region quantitatively, by defining a region of interest between Bregma $-1.70 \mathrm{~mm}$ and $-2.06 \mathrm{~mm}$ (rostro-caudal level, Paxinos) in the upper half of the neocortex (see Suppl. Fig. 1 and Methods for details). In order to investigate whether the PV deficiency in the neocortex was generally present in other brain regions, we analyzed PV-cell numbers in the hippocampal CA1 area beneath the affected cortex (same rostro-caudal level; see Suppl. Fig. 1 and Methods for details of the region of interest). We found no significant difference of PV-cell densities in CA1 between VPA- and saline-treated animals (Fig. 2b).

Strikingly, PV-empty zones were primarily found to affect only one hemisphere, while the neighboring hemisphere at the same rostro-caudal level seemed to be intact (Fig. 3a). We therefore compared the visibly affected hemisphere of VPA mice to either side of saline-treated control animals. This analysis revealed a highly significant reduction of PV-cells by prenatal VPA exposure (Fig. 2b). A lack of PV-cells in one but not the other hemisphere suggests a strong imbalance in fast, perisomatic inhibition between the two sides of the brain. To quantify the extent of this imbalance, we calculated the interhemispheric ratio (PV-cell number in the hemisphere with lower density / PV-cell number in the opposite hemisphere). While saline-exposed animals exhibited interhemispheric ratios close to unity, VPA-exposed mice exhibited a robust $50 \%$ reduction of $\mathrm{PV}$-cells in one of the two hemispheres. To determine if this imbalance was general, we compared PV-cell densities in the hippocampal CA1 region. No significant difference in interhemispheric ratios between VPA- and saline-treated mice were found in area CA1, indicating a neocortex-specific deficit.

To address the possibility that the lack of PV-cells in neocortex and an interhemispheric imbalance in inhibitory circuits is a more robust hallmark of ASD models, we investigated a single-gene mutation model of ASD, the 
a
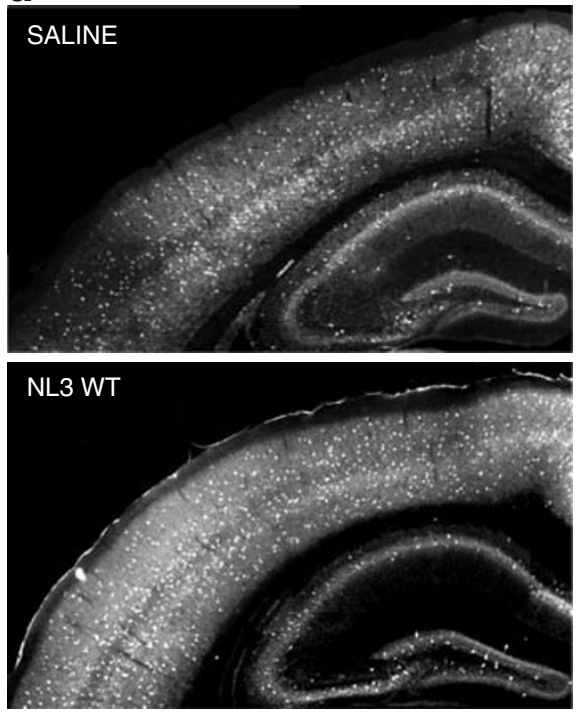
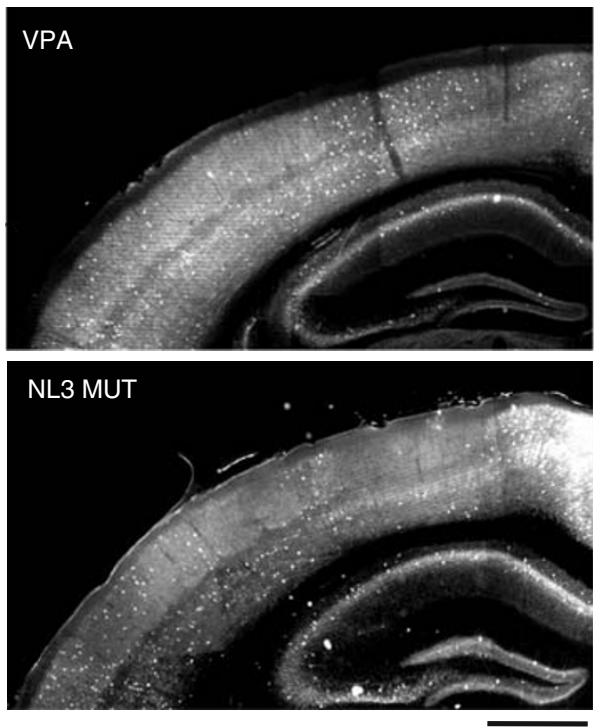

b

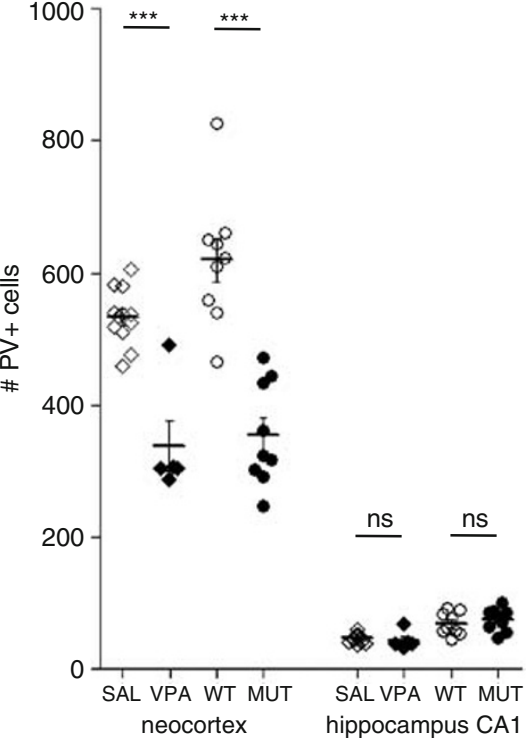

Fig. 2 PV-cell deficit in VPA and NL-3 mutant mice. a Representative photomicrographs of PV immunohistochemistry in coronal sections of saline-treated (SAL; top left), valproic acid-treated (VPA; top right) Neuroligin3 wildtype (NL3 WT; bottom left) and mutant (NL3 MUT; bottom right) mice. Scale bar: $500 \mu \mathrm{m}$. b Quantitative analysis of PV-cells in neocortex and hippocampal CA1 (see Suppl.

NL-3 R451C mutant mouse [6]. We found that NL-3 mutant mice exhibited very similar PV-cell deficiency and interhemispheric imbalance as in the VPA model. NL-3 mutant mice were analyzed in the same way as described
Fig. 1 and Mehods for details). For all animals, the hemisphere with the lowest PV+ cell numbers was plotted. Note the specific reduction of PV-cells in the neocortex of VPA-treated and NL3 mutant mice. One-way ANOVA test: $* * * p<0.0001$; Bonferroni multiple comparison test, $p<0.001$; ns $=$ not significant

above for prenatal VPA-treated animals. Once again, a highly significant reduction of PV-cells in one hemisphere was observed specific to the neocortex, as it was absent from underlying CA1 (Fig. 2b). Inter-hemispheric ratios of a
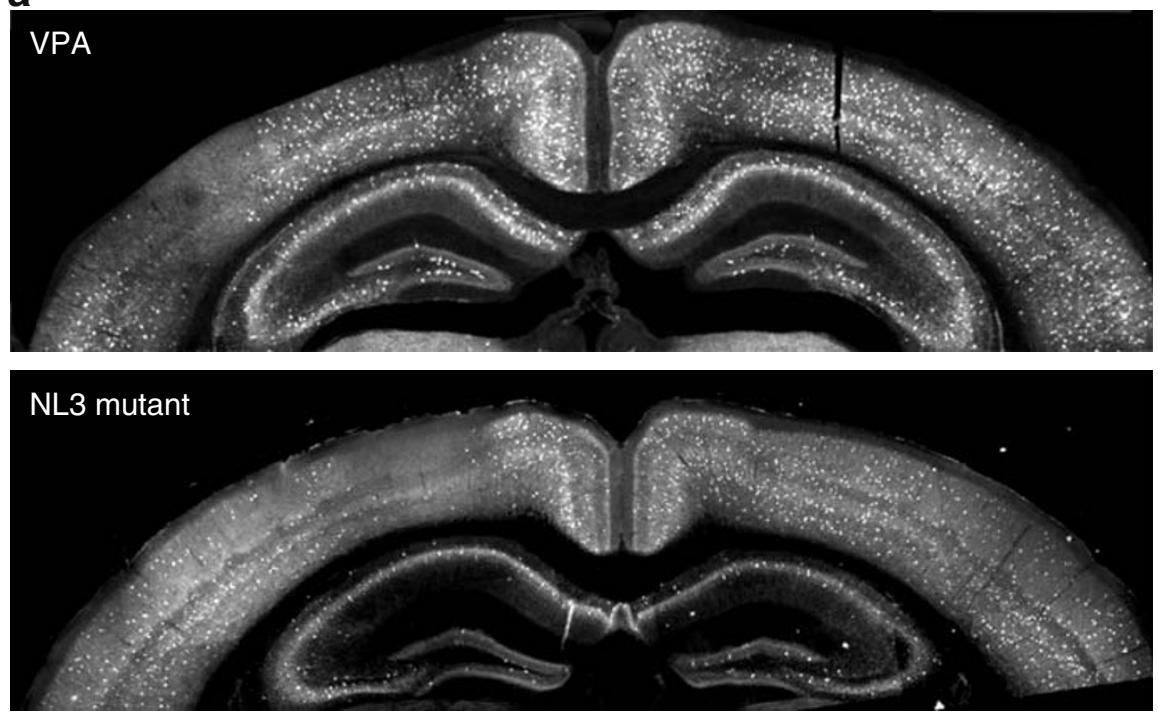

b

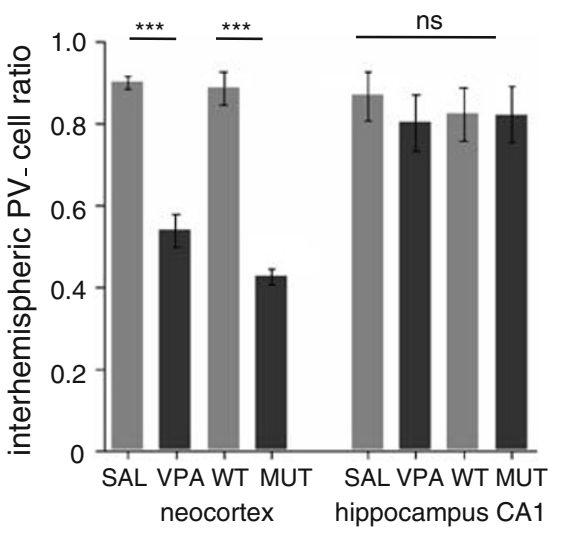

Fig. 3 Interhemispheric asymmetry of PV-cell deficit in VPA and NL-3 mutant mice. a Representative photomicrographs of PV immunohistochemistry in coronal sections of valproic acid treated (VPA; top) and Neuroligin3 mutant (NL3 MUT; bottom) mice. Note the difference in PV-cells in the two hemispheres. Scale bar: $500 \mu \mathrm{m}$. b Interhemispheric PV ratios calculated by dividing PV-cell numbers in the two hemispheres at the same anterior-posterior level (ratio= $\mathrm{PV}$ low density/PV high density hemisphere). One-way ANOVA test: $* * * p<0.0001$; Bonferroni multiple comparison test, $p<0.001$; ns =not significant; SAL, saline control; WT, wild-type 
PV-cell numbers in NL-3 mutant mice were reduced $>50 \%$ specifically in the neocortex (Fig. 3). Whether hemispheric asymmetries of PV-cells are evident in other ASD mouse models (Table 1) remains to be explored.

We further confirmed an increase of GAD65 puncta in the NL-3 mutant (Suppl. Fig. 2), consistent with the original report by Tabuchi et al [6]. Normally, PV regulates the dynamics of calcium levels and GABA release during action potential bursts in this specific interneuron subset [30]. Interestingly, PV knockout mice themselves have recently been reported to exhibit autistic features (B. Schwaller, personal communication). A loss of PV expression in VPAtreated or NL-3 mutant mice may then exacerbate an E/I imbalance in favor of inhibition [6], as in other models of ASD (Table 1). Thus, disparate genetic origins may underlie a common circuit defect in ASD.

\section{Impact of PV-cell defects in ASD}

Unlike principal excitatory neurons, GABAergic interneurons comprise a diverse group that consists of dozens of different types. Cortical interneuron subtypes can be classified by their morphology, electrophysiological properties, molecular content and specific connectivity patterns. The PV-positive, large basket cells have been implicated in two functions (Fig. 4): 1) initiation of a critical period for cortical plasticity [1], and 2) generation and synchronization of gamma $(\gamma)$-oscillations in the hippocampus and neocortex [31]. Both phenomena have been suggested to be impaired in the etiology of cognitive developmental disorders such as ASD, and can strikingly both be accounted for by the common PV-cell deficit reported here.
Critical periods

Hubel and Wiesel were among the first to find physiological evidence for developmental time windows when specific brain circuits are more susceptible to experience-dependent changes [1]. Monocular occlusion of one eye produces a shift of neuronal response (ocular dominance) in favor of the open eye only when deprivation occurs during a specific 'critical period'. Since then critical periods have been identified across a variety of brain regions, sensory systems and species [32]. Electrophysiological recording and morphological analyses in vivo in genetically manipulated mice have furthered our understanding of the mechanisms and demonstrated the importance of PV-cells.

Beginning with the discovery that GABA-deficient GAD65 knockout mice do not initiate a critical period and that this deficit could be rescued at any age with diazepam $[7,8]$, the theory emerged that a requisite E/I balance within the cortex enables plasticity at the appropriate time (Fig. 4a). Diazepam is a positive allosteric modulator of $\mathrm{GABA}_{\mathrm{A}}$ channels that binds specific subunits to increase channel open probability and increase inhibition. Diazepam administration can prematurely open the critical period of wild-type mice, but targeted point mutation of the $\alpha 1$ receptor subunit prevents diazepam binding as well as its precocious initiation of plasticity [9]. $\mathrm{GABA}_{\mathrm{A}}$ receptors containing the $\alpha 1$ subunit are located on the soma-proximal dendrite region of pyramidal cells. PVlarge basket cells preferentially target the same area (Fig. 1), which undergoes an experience-dependent regulation of receptor number during the critical period [10]. The non-cell autonomous homeoprotein Otx2 is crucial for the

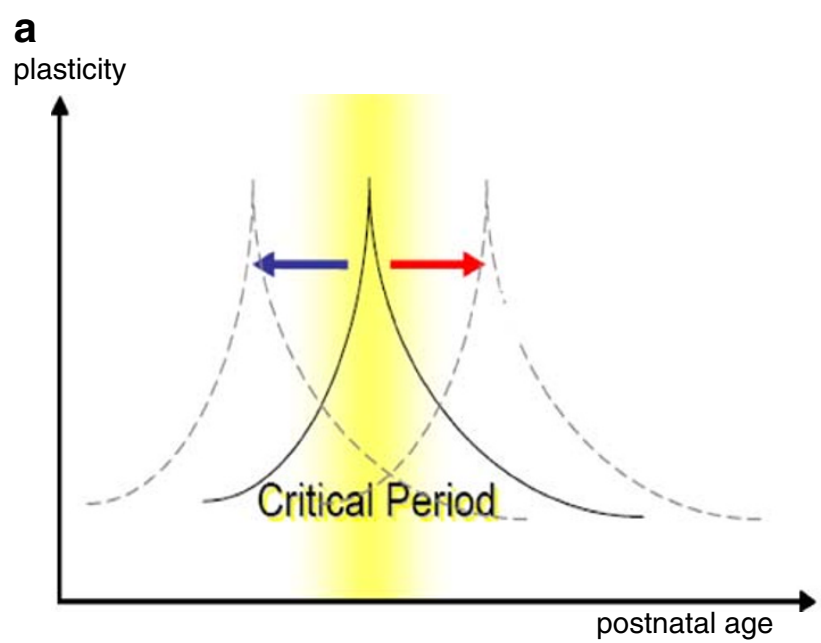

Fig. 4 Two functions of PV-cells that might be altered in ASD mouse models. a Initiation of critical periods of brain development may be delayed or accelerated in specific regions exhibiting PV-cell deficits. b Generation of $\gamma$-oscillations during cognition and sensory processing b

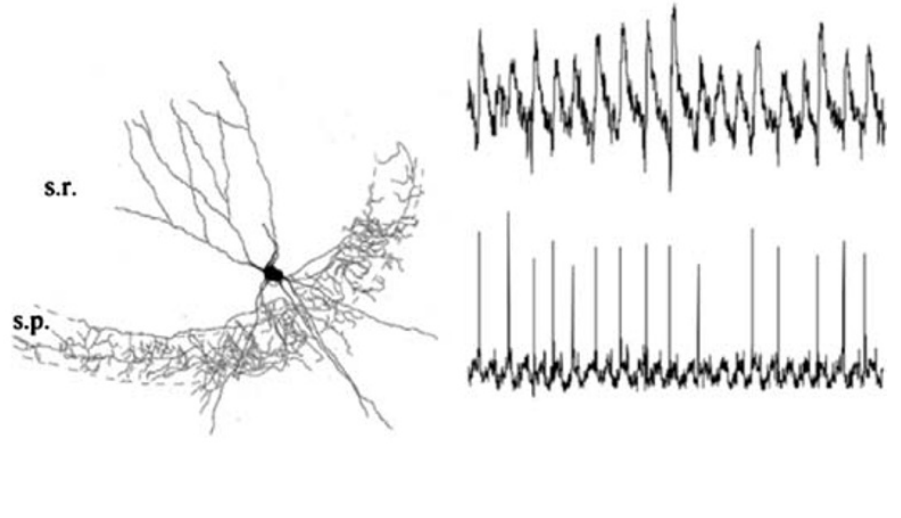

may be dampened asymmetrically across hemispheres, potentially impairing long-range synchronization and communication [64, 80, 81]. Adapted from ref. 61 
maturation of PV-cells and, consistently is an essential transcription factor for critical period initiation [11].

Taken together, these findings underscore the crucial role PV-cells play in timing neocortical plasticity (Fig. 4a), suggesting that PV-cell deficits may predictably delay critical periods in specific ASD brain regions (Table 1). Rescue of ASD models, such as the FMR1 knockout mouse by mGluR5 manipulation [33], can then be reconsidered in terms of rebalancing PV-cell recruitment, as mGluR5 is essential for long-term potentiation of excitatory synapses onto these fast-spiking GABAergic neurons [34]. Other direct strategies to enhance PV-cell function, such as benzodiazepine agonists or the delivery of Otx2 [11], may also prove fruitful. Conversely, to recalibrate PV-cell discrepancies across hemispheres in adult mice (Fig. 3), the administration of chondrotinases to remove peri-neuronal nets that preferentially enwrap mature PV-basket cells may be effective [17].

\section{Gamma oscillations}

EEG gamma $(\gamma)$-oscillations $(30-80 \mathrm{~Hz}$ fluctuations of neuronal activity) have received special attention because of their suspected roles in "higher" cognitive functions such as sensory binding [35], short-term memory storage [36] and attention [37, 38]. $\gamma$-oscillations are prevalent in the hippocampus and sensory cortex and have been studied both in vivo and in vitro. They are generated or reset in vivo by sensory stimulation in mouse visual, auditory and somatosensory cortex [39-41], exploratory behavior, sniffing in rodents, visual attention in primates and during REM sleep [38, 42]. Persistent $\gamma$-oscillations can be stimulated in vitro with carbachol to activate muscarinic cholinergic receptors or by application of kainate to increase excitability of glutamatergic receptors $[43,44]$. They are also reliably generated in slices of auditory and somatosensory cortex by thalamic stimulation, but are short in duration (200-500 ms) [45].

Regardless of stimulus protocol, $\gamma$-oscillations can be abolished by application of the $\mathrm{GABA}_{\mathrm{A}} \mathrm{R}$ antagonist bicuculline [31]. Current-source density analysis combined with voltage-dye imaging reveal an alternating current sink and source near pyramidal cell somata, consistent with perisomatic inhibition during the oscillation [42]. When excitatory drive is selectively reduced onto PV-cells either by GluR-D knockout or conditional ablation of GluR-A subunit of their AMPA receptors, $\gamma$-power is reduced [46], but not when synaptic inhibition is ablated in PV-cells [47]. Most recently, direct optical activation of PV-cells is shown to be sufficient for inducing $\gamma$-rhythms and controlling sensory responses to enhance cortical circuit performance [48, 49].

Both chandelier and large basket PV-cells are fast-spiking (FS) cells that are interconnected via gap junctions and inhibitory chemical synapses to form distributed networks.
FS-cells have short duration action potentials and respond to a depolarizing current with high frequency, non-adapting action potential trains $[51,52]$. PV-cells express $\mathrm{K}_{\mathrm{v}} 3.1$ channels, a class of inward rectifying $\mathrm{K}^{+}$channels that contributes to their fast-spiking characteristics. PV-cells normally undergo maturation of a number of intrinsic physiological properties that contribute to their precise and rapid firing including an experience-dependent increase in $\mathrm{K}_{\mathrm{v}} 3.1$ channels [50], a decrease in input resistance and action potential width and an increase in action potential amplitude and frequency [53, 54]. $\mathrm{K}_{\mathrm{v}} 3.1$ knockout mice exhibit an increase in $\gamma$-power, most prominently during waking in the $40-55-\mathrm{Hz}$ range [55].

Gap junctions strongly aid the synchrony and strength of $\gamma$-oscillations, since the blockers octanol and carbexenolone eliminate oscillations [56, 57], but deletion of the major neuronal gap junction subunit, connexin 36 , still allows weak and less synchronous $\gamma$-oscillations both in vitro [58] and in vivo [59]. Careful study of the spike timing of different classes of interneurons has shown that while both excitatory and different classes of inhibitory neuron are capable of firing phase-locked with the $\gamma$-oscillation, inhibitory neurons are more likely to be synchronized with FS interneurons capable of firing on every cycle (Fig. 4b) [60, 61].

These findings lead to a model of a network of interconnected inhibitory neurons, namely the PV-basket cells, which generate the $\gamma$-oscillations [31]. Sensory information is relayed from the environment and earlier peripheral stages to the cortex via the thalamus. Thalamocortical fibers target both principal cells and interneurons, but input onto FS-cells is stronger than that onto excitatory pyramidal cells [62]. Fast, precise inhibition provided by the PV-cells allows a brief window for excitation of the cortical network that is followed by an interval of strong inhibition. Gap junctions and reciprocal chemical GABA synapses connecting PV-cells meanwhile act as coincidence detectors, amplifying synchronous excitatory currents and dampening asynchronous inputs [63]. Asymmetrically weakened PV-cell function in the ASD brain (Fig. 3) would then be expected to have a powerful impact on sensory processing and cognition [64].

Impaired oscillations in cognitive disorders

A dysregulation of oscillations could prevent discrimination of intrinsic versus extrinsic signals [65]. In schizophrenic subjects, abnormal $\gamma$-oscillations are thought to promote hallucinations. Decreased GABA signaling is now wellestablished in schizophrenia [66], which is seen not only as a reduction of GABA concentration and GAD67 in postmortem brain, but also as a restricted deficit of PV staining [67, 68]. A specific association between disrupted $\gamma$-oscillations, PV-cell reduction, and schizophrenic traits has recently been demonstrated in the methyl azoxy- 
methanol acetate (MAM) model of schizophrenia. These rats exhibit a specific loss of PV-cells in the prefrontal cortex and a correlated lack of sound induced $\gamma$-oscillations in the prefrontal cortex during a fear-conditioning task [69].

In auditory cortex of autistic adolescents, magnetoencephalographic (MEG) recordings show a deficit of evoked $\gamma$-oscillations phase-locked to the stimulus strikingly just in one hemisphere [70]. A similar finding that the onset of $\gamma$-oscillations during a visual task is disrupted in autism, suggests that there are signal-to-noise processing problems $[71,72]$. Of particular relevance is the recent finding that visual attention preferentially modulates FS interneurons in parietal areas [73], which we find are prone to PV-cell deficits in ASD mouse models (Table 1).

Clinical studies suggest that decreased inhibitory input and connectivity lead to altered synchronicity between different brain regions, which may be a key contributing factor to the features of ASD [35, 64, 74-76]. Consistent anatomical evidence reveals narrower cortical minicolumns in autistic patients [77-79] due to the loss of local inhibitory projections [77]. This may result in further altered long-range connectivity [80,81], vital for communication between neocortical modules and hemispheres [74, 82-85].

Interestingly, among several inbred strains [86], it is the acallosal BTBR $\mathrm{T}+\mathrm{tf} / \mathrm{J}$ mouse that most closely exhibits behavioral changes specific to autism, including reduced social approach, altered ultrasonic vocalization, and resistance to change in routine [87]. Moreover, network architecture and synchronicity are altered in cultured neuronal networks transfected with the autism-associated R451C NL-3 mutation studied here [88]. The MeCP2-null hippocampal CA3 circuit has diminished basal inhibitory rhythmic activity, which in turn renders the circuitry prone to hyperexcitability [89]. Finally, a recent report demonstrates that $\gamma$-oscillations are diminished in the FMR1 knockout mouse model of ASD [90], consistent with their PV-cell deficit (Table 1).

Thus, studying $\gamma$-oscillation development in ASD mouse models can serve as a useful readout of impaired PV-cell network activity, which is now amenable to powerful, direct molecular genetic manipulation [eg. 91]. Future work will explore the hemispheric asymmetry in VPA or NL-3 mutant mice described here, whether this can be rescued by treatments aimed at restoring PV-cell balance [11, 17] and ultimately reversing this heterogeneous neuro-developmental disorder [92, 93].

\section{Materials and methods}

Animals

C57BL/6 females were mated overnight with C57BL/6 males and pregnancy was determined by the presence of a vaginal plug on embryonic day E0. Valproic Acid (VPA) solution was prepared from sodium salt of VPA (NaVPA; Sigma-Aldrich, St. Louis, MO) and was dissolved in $0.9 \%$ saline to a final concentration of $150 \mathrm{mg} / \mathrm{mL}$ at $\mathrm{pH} 7.3$. At E10.5, pregnant females were briefly anesthetized with isofluorane and injected intraperitoneally with either a single dose of VPA or $0.9 \%$ saline (control). Mice were weighed prior to injection and the volume was adjusted for a final dose of $500 \mathrm{mg} / \mathrm{kg}$. This dose and time point is identical to the conditions used in previous studies with rats [22]. NL-3 R451C mice were bred, genotyped and maintained as described previously [6]

\section{Immunohistochemistry}

Adult mice (2-3 months old) were transcardially perfused with ice-chilled $4 \%$ paraformaldehyde in PBS $(50 \mathrm{ml})$ and post-fixed overnight in the same solution at $4{ }^{\circ} \mathrm{C}$. Sixty $\mu \mathrm{m}$ thick coronal sections were cut on a Vibratome (Leica VT1000S). Free-floating sections were permeabilized and blocked for 4 hours at room temperature (RT) in 20\% Bovine Serum Albumin (BSA) / 0.5\% TritonX100 in PBS. Sections were then incubated with primary, rabbit anti-Parvalbumin (PV) (Swant) or GAD6 (DSHB, Iowa), and subsequently secondary, Alexa Fluor 546 (Invitrogen), antibodies (3-4 $\mathrm{h}$ each at RT, 1:500 (PV), 1:1000 (Alexa Fluor) in 5\% BSA in PBS). Between and after antibody incubations, sections were washed $3 \mathrm{x}, 10 \mathrm{~min}$ each, in $5 \%$ BSA in PBS on a shaker. Sections were then mounted in Vectashield Hard Set (Vector Laboratories) and imaged.

Image acquisition and analysis

Images were acquired on a Nikon Eclipse 80i epifluorescent microscope equipped with a Coolsnap EZ camera (Photometrics) and AR acquisition software (NIS Elements) using a $4 \mathrm{x}$ air objective. Microscope images were processed and analyzed using Photoshop (Adobe). For quantification, images of the upper half of coronal brain sections, collected between Bregma $-1.70 \mathrm{~mm}$ and $-2.06 \mathrm{~mm}$ (anteriorposterior level, Paxinos), were taken (Suppl. Fig. 1). PVpositive cells were counted in the neocortex and in the hippocampal area CA1. Regions of interest were defined by perpendicular lines along the upper blade and outer edge of the dentate gyrus curve (Suppl. Fig. 1). PV-positive cells were counted separately for the two hemispheres. Analysis was performed blind to genotype or treatment by two independent investigators.

Acknowledgments We thank the Simons Foundation (TKH, NG) and HFSP (NG) for funding, and Michael Marcotrigiano for technical support. 


\section{References}

1. Hensch TK. Critical period plasticity in local cortical circuits. Nat Rev Neurosci. 2005;6:877-88.

2. Zoghbi HY. Postnatal neurodevelopment disorders: meeting at the synapse? Science. 2003;302:826-30.

3. Canitano R. Epilepsy in autism spectrum disorders. Eur Child Adolesc Psychiatry. 2007;16:61-6.

4. Rubenstein J, Merzenich M. Model of autism: increased ratio of excitation/inhibition in key neural systems. Genes, Brain, and Behavior. 2003;2(5):255-67.

5. Ramocki MB, Zoghbi HY. Failure of neuronal homeostasis results in common neuropsychiatric phenotypes. Nature. 2008;455:912-8.

6. Tabuchi $\mathrm{K}$, et al. A neuroligin-3 mutation implicated in autism increases inhibitory synaptic transmission in mice. Science. 2007;318:71-6.

7. Fagiolini M, Hensch TK. Inhibitory threshold for critical-period activation in primary visual cortex. Nature. 2000;404:183-6.

8. Iwai Y, Fagiolini M, Obata K, Hensch TK. Rapid critical period induction by tonic inhibition in visual cortex. J Neurosci. 2003;23:6695-6702.

9. Fagiolini M, Fritschy JM, Low K, Mohler H, Rudolph U, Hensch TK. Specific GABAA circuits for visual cortical plasticity. Science. 2004;303:1681-83.

10. Katagiri H, Fagiolini M, Hensch TK. Optimization of somatic inhibition at critical period onset in mouse visual cortex. Neuron. 2007;53:805-12.

11. Sugiyama S, et al. Experience-dependent transfer of Otx2 homeoprotein into the visual cortex activates postnatal plasticity. Cell. 2008;134(3):508-20.

12. Gonchar Y, Wang Q, Burkhalter A. Multiple distinct subtypes of GABAergic neurons in mouse visual cortex identified by triple immunostaining. Front Neuroanat. 2007;1:3.

13. Butt SJ, Fuccillo M, Nery S, Noctor S, Kriegstein A, Corbin JG, et al. The temporal and spatial origins of cortical interneurons predict their physiological subtype. Neuron. 2005;48:591-604.

14. Del Rio J, et al. The development of parvalbumin-immunoreactivity in the neocortex of the mouse. Brain Research Development. 1994;81(2):247-59.

15. Hartig W, Derouiche A, Welt K, Brauer K, Grosche J, Mader M, et al. Cortical neurons immunoreactive for the potassium channel Kv3.1b subunit are predominantly surrounded by perineuronal nets presumed as a buffering system for cations. Brain Res. 1999;842:15-29.

16. Galtrey CM, Fawcett JW. The role of chondroitin sulfate proteoglycans in regeneration and plasticity in the central nervous system. Brain Res Rev. 2007;54:1-18.

17. Pizzorusso T, et al. Reactivation of ocular dominance plasticity in the adult visual cortex. Science. 2002;298(5596):1248-51.

18. Losh M, Sullivan PF, Trembath D, Piven JJ. Current developments in the genetics of autism: from phenome to genome. Neuropathol Exp Neurol. 2008;67:829-37.

19. Christianson AL, Chesler N, Kromberg JG. Fetal valproate syndrome: clinical and neuro-developmental features in two sibling pairs. Dev Med Child Neurol. 1994;36:361-9.

20. Hyman S, Arndt TL, Rodier PM. Enviromental agents and autism: once and futilure associations. International Review of Research in Mental Retardation. 2006;30:171-94.

21. Miyazaki K, Narita N, Narita N. Maternal administration of thalidomide of valproic acid causes abnormal serotonergic neurons in the offspring: implication for pathogenesis of autism. International Jornal of Developmental Neuroscience. 2005;23:287-97.

22. Rinaldi T, et al. Elevated NMDA receptor levels and enhanced postsynaptic long-term potentiation induced by prenatal exposure to valproic acid. PNAS. 2007;104(33):13501-6.
23. Markram K, Rinaldi T, La Mendola D, Sandi C, Markram H. Abnormal fear conditioning and amygdala processing in an animal model of autism. Neuropsychopharmacology. 2008;33 (4):901-12.

24. Wagner $\mathrm{G}$, et al. A new neurobehavioral model of autism in mice: pre- and postnatal exposure to sodium valproate. Journal of Developmental Disorders. 2006;36:779-93.

25. Yochum C, et al. VPA-induced apoptosis and behavioral deficits in neonatal mice. Brain Res. 2008;1203:126-32.

26. Nadler J, et al. Automated apparatus for quantitation of social approach behaviors in mice. Genes, Brain, and Behavior. 2004;3 (5):303-14.

27. Scattoni M, et al. Ultrasonic vocalizations: a tool for behavioural phenotyping of mouse models of neurodevelopmental disorders. Neuroscience Biobehavioral Review 2008a. doi:10.1016/j. neubiorev.2008.08.003.

28. Jamain S, et al. Mutations of the X-linked genes encoding neuroligins NLGN3 and NLGN4 are associated with autism. Nat Genet. 2003;34(1):27-9.

29. Chadman K, et al. Minimal aberrant behavioral phenotypes of neuroligin-3 R451C knockin mice. Autism Research. 2008;1:14758.

30. Vreugdenhil M, et al. Parvalbumin-deficiency facilitates repetitive IPSCs and gamma oscillations in the hippocampus. J Neurophysiol. 2003;89(3):1414-22.

31. Bartos M, Vida I, Jonas P. Synaptic mechanisms of synchronized gamma oscillations in inhibitory interneuron networks. Nat Rev Neurosci. 2007;8:45-56.

32. Hensch TK. Critical period regulation. Annu Rev Neurosci. 2004;27:549-79.

33. Dolen G, Osterweil E, Rao BS, Smith GB, Auerbach BD, Chattarji $\mathrm{S}$, et al. Correction of Fragile $\mathrm{X}$ syndrome in mice. Neuron. 2007;56:955-62.

34. Sarihi A, Jiang B, Komaki A, Sohya K, Yanagawa Y, Tsumoto T. Metabotropic glutamate receptor type 5-dependent long-term potentiation of excitatory synapses on fast-spiking GABAergic neurons in mouse visual cortex. J Neurosci. 2008;28:1224-35.

35. Singer W. Synchronization of cortical activity and its putative role in information processing and learning. Annu Rev Physiol. 1993;55:349-74.

36. Lisman JE, Idiart MA. Storage of $7+/-2$ short-term memories in oscillatory subcycles. Science. 1995;267:1512-15.

37. Murthy VN, Fetz EE. Coherent $25-$ to $35-\mathrm{Hz}$ oscillations in the sensorimotor cortex of awake behaving monkeys. Proc Natl Acad Sci USA. 1992;89:5670-74.

38. Fries P, Reynolds JH, Rorie AE, Desimone R. Modulation of oscillatory neuronal synchronization by selective visual attention. Science. 2001;291:1560-63.

39. Nase G, Singer W, Monyer H, Engel AK. Features of neuronal synchrony in mouse visual cortex. J Neurophysiol. 2003;90:111523.

40. MacDonald KD, Barth DS. High frequency (gamma-band) oscillating potentials in rat somatosensory and auditory cortex. Brain Res. 1995;694:1-12.

41. Ribary U. Dynamics of thalamo-cortical network oscillations and human perception. Prog Brain Res. 2005;150:127-42.

42. Mann EO, Paulsen O. Mechanisms underlying gamma ('40 Hz’) network oscillations in the hippocampus - a mini-review. Prog Biophys Mol Biol. 2005;87:67-76.

43. Buhl EH, Tamas G, Fisahn A. Cholinergic activation and tonic excitation induce persistent gamma oscillations in mouse somatosensory cortex in vitro. J Physiol. 1998;513(Pt 1):117-26.

44. Cunningham MO, Whittington MA, Bibbig A, Roopun A, LeBeau FE, Vogt A, et al. A role for fast rhythmic bursting neurons in cortical gamma oscillations in vitro. Proc Natl Acad Sci USA. 2004;101:7152-57. 
45. Metherate R, Cruikshank SJ. Thalamocortical inputs trigger a propagating envelope of gamma-band activity in auditory cortex in vitro. Exp Brain Res. 1999;126:160-74.

46. Fuchs EC, Zivkovic AR, Cunningham MO, Middleton S, Lebeau FE, Bannerman DM, et al. Recruitment of parvalbumin-positive interneurons determines hippocampal function and associated behavior. Neuron. 2007;53:591-604.

47. Wulff P, Ponomarenko AA, Bartos M, Korotkova TM, Fuchs EC, Bähner F, et al. Hippocampal theta rhythm and its coupling with gamma oscillations require fast inhibition onto parvalbuminpositive interneurons. Proc Natl Acad Sci USA. 2009;106:3561-6.

48. Cardin JA, Carlén M, Meletis K, Knoblich U, Zhang F, Deisseroth K, Tsai LH, Moore CI. Driving fast-spiking cells induces gamma rhythm and controls sensory responses. Nature 2009; in press.

49. Sohal VS, Zhang F, Yizhar O, Deisseroth K. Parvalbumin neurons and gamma rhythms enhance cortical circuit performance. Nature 2009; in press.

50. Grabert J, Wahle P. Visual experience regulates $\mathrm{Kv} 3.1 \mathrm{~b}$ and Kv3.2 expression in developing rat visual cortex. Neuroscience. 2009;158:654-64.

51. Kawaguchi Y, Kubota Y. Correlation of physiological subgroupings of nonpyramidal cells with parvalbumin- and calbindinD28kimmunoreactive neurons in layer $\mathrm{V}$ of rat frontal cortex. J Neurophysiol. 1993;70:387-96.

52. Kawaguchi Y. Physiological subgroups of nonpyramidal cells with specific morphological characteristics in layer II/III of rat frontal cortex. J Neurosci. 1995;15:2638-55.

53. Plotkin JL, $\mathrm{Wu} \mathrm{N}$, Chesselet MF, Levine MS. Functional and molecular development of striatal fast-spiking GABAergic interneurons and their cortical inputs. Eur J Neurosci. 2005;22:1097-108.

54. Doischer D, Hosp JA, Yanagawa Y, Obata K, Jonas P, Vida I, et al. Postnatal differentiation of basket cells from slow to fast signaling devices. J Neurosci. 2008;28:12956-68.

55. Joho RH, Ho CS, Marks GA. Increased gamma- and decreased delta-oscillations in a mouse deficient for a potassium channel expressed in fast-spiking interneurons. J Neurophysiol. 1999; 82:1855-64.

56. Traub RD, Bibbig A. A model of high-frequency ripples in the hippocampus based on synaptic coupling plus axon-axon gap junctions between pyramidal neurons. J Neurosci. 2000;20:2086-93.

57. Traub RD, Kopell N, Bibbig A, Buhl EH, LeBeau FE, Whittington MA. Gap junctions between interneuron dendrites can enhance synchrony of gamma oscillations in distributed networks. J Neurosci. 2001;21:9478-86.

58. Hormuzdi SG, Pais I, LeBeau FE, Towers SK, Rozov A, Buhl EH, et al. Impaired electrical signaling disrupts gamma frequency oscillations in connexin 36-deficient mice. Neuron. 2001;31:487-95.

59. Buhl DL, Harris KD, Hormuzdi SG, Monyer H, Buzsaki G. Selective impairment of hippocampal gamma oscillations in connexin-36 knock-out mouse in vivo. J Neurosci. 2003;23:1013-18.

60. Csicsvari J, Jamieson B, Wise KD, Buzsaki G. Mechanisms of gamma oscillations in the hippocampus of the behaving rat. Neuron. 2003;37:311-22.

61. Hajos N, Palhalmi J, Mann EO, Nemeth B, Paulsen O, Freund TF. Spike timing of distinct types of GABAergic interneuron during hippocampal gamma oscillations in vitro. J Neurosci. 2004;24:9127-37.

62. Cruikshank SJ, Lewis TJ, Connors BW. Synaptic basis for intense thalamocortical activation of feedforward inhibitory cells in neocortex. Nat Neurosci. 2007;10:462-8.

63. Galarreta M, Hestrin S. Spike transmission and synchrony detection in networks of GABAergic interneurons. Science. 2001;292:2295-9.

64. Uhlhaas P, Singer W. What do disturbances in neural synchrony tell us about autism? Biol Psychiatry. 2006;62:190-1.
65. Behrendt RP. Hallucinations: synchronisation of thalamocortical gamma oscillations under-constrained by sensory input. Conscious Cogn. 2003;12:413-51.

66. Lewis DA, Hashimoto T, Volk DW. Cortical inhibitory neurons and schizophrenia. Nat Rev Neurosci. 2005;6:312-24.

67. Lisman JE, Coyle JT, Green RW, Javitt DC, Benes FM, Heckers $\mathrm{S}$, et al. Circuit-based framework for understanding neurotransmitter and risk gene interactions in schizophrenia. Trends Neurosci. 2008;31:234-42.

68. Gonzalez-Burgos G, Lewis DA. GABA neurons and the mechanisms of network oscillations: implications for understanding cortical dysfunction in schizophrenia. Schizophr Bull. 2008;34:944-61.

69. Lodge DJ, Behrens MM, Grace AA. A loss of parvalbumincontaining interneurons is associated with diminished oscillatory activity in an animal model of schizophrenia. J Neurosci. 2009;29:2344-54.

70. Wilson TW, Rojas DC, Reite ML, Teale PD, Rogers SJ. Children and adolescents with autism exhibit reduced MEG steady-state gamma responses. Biol Psychiatry. 2007;62:192-7.

71. Brown C, Gruber T, Boucher J, Rippon G, Brock J. Gamma abnormalities during perception of illusory figures in autism. Cortex. 2005;41:364-76.

72. Grice $\mathrm{S}$, et al. Disordered visual processing and oscillatory brain activity in autism and Williams syndrome. Neuroreport. 2001;12:2697-700

73. Mitchell JF, Sundberg KA, Reynolds JH. Differential attentiondependent response modulation across cell classes in macaque visual area V4. Neuron. 2007;55:131-41.

74. Rippon G, Brock J, Brown C, Boucher J. Disordered connectivity in the autistic brain: challenges for the "new psychophysiology". Int J Psychophysiol. 2007;63:164-72.

75. Welsh JP, Ahn ES, Placantonakis DG. Is autism due to brain desynchronization? Int J Dev Neurosci. 2005;23:253-63.

76. Just MA, Cherkassky VL, Keller TA, Minshew NJ. Cortical activation and synchronization during sentence comprehension in high-functioning autism: evidence of underconnectivity. Brain. 2004;127:1811-21.

77. Casanova MF, Buxhoeveden D, Gomez J. Disruption in the inhibitory architecture of the cell minicolumn: implications for autism. Neuroscientist. 2003;9:496-507.

78. Casanova MF. The neuropathology of autism. Brain Pathol. 2007;17:422-33.

79. Pardo CA, Eberhart CG. The neurobiology of autism. Brain Pathol. 2007;17:434-47.

80. Geschwind DH, Levitt P. Autism spectrum disorders: developmental disconnection syndromes. Curr Opin Neurobiol. 2007;17:103-11.

81. Courchesne E, Pierce K. Why the frontal cortex in autism might be talking only to itself: local over-connectivity but long-distance disconnection. Curr Opin Neurobiol. 2005;15:225-30.

82. Brock J, Brown CC, Boucher J, Rippon G. The temporal binding deficit hypothesis of autism. Dev Psychopathol. 2002;14:209-24.

83. Muller RA, Kleinhans N, Kemmotsu N, Pierce K, Courchesne E. Abnormal variability and distribution of functional maps in autism: an FMRI study of visuomotor learning. Am J Psychiatry. 2003;160:1847-62.

84. Koshino H, Carpenter PA, Minshew NJ, Cherkassky VL, Keller TA, Just MA. Functional connectivity in an fMRI working memory task in high-functioning autism. Neuroimage. 2005;24:810-21.

85. Koshino H, Kana RK, Keller TA, Cherkassky VL, Minshew NJ, Just MA. fMRI investigation of working memory for faces in autism: visual coding and underconnectivity with frontal areas. Cereb Cortex. 2008;18:289-300.

86. Moy S, et al. Mouse behavioral tasks relevant to autism: phenotypes of 10 inbred strains. Behav Brain Res. 2007;176:4-20. 
87. McFarlane H, et al. Autism-like behavioral phenotypes in BTBR $\mathrm{T}+\mathrm{tf} / \mathrm{J}$ mice. Genes, Brain, and Behavior. 2008;7:152-63.

88. Herrera CG, Hung J, Zhang Y, Kertesz AC, Espina FJ, Colicos MA. Altered synchrony and connectivity in neuronal networks expressing an autism-related mutation of neuroligin 3. Neuroscience 2009; in press.

89. Zhang L, He J, Jugloff DG, Eubanks JH. The MeCP2-null mouse hippocampus displays altered basal inhibitory rhythms and is prone to hyperexcitability. Hippocampus. 2008;18:294309.

90. Gibson JR, Bartley AF, Hays SA, Huber KM. Imbalance of neocortical excitation and inhibition and altered UP states reflect network hyperexcitability in the mouse model of fragile $\mathrm{X}$ syndrome. J Neurophysiol. 2008;100:2615-26.

91. Kuhlman SJ, Huang ZJ. High-resolution labeling and functional manipulation of specific neuron types in mouse brain by Creactivated viral gene expression. PLoS ONE. 2008;3:e2005.

92. Polleux F, Lauder J. Toward a developmental neurobiology of autism. Mental Retard Dev Dis. 2004;10:303-17.

93. Levitt $P$, et al. Regulation of neocortical interneuron development and the implications for neurodevelopmental disorders. Trends Neurosci. 2004;27:400-6.
94. Selby L, et al. Major defects in neocortical GABAergic inhibitory circuits in mice lacking the fragile $\mathrm{X}$ mental retardation protein. Neurosci Letters. 2007;412:227-32.

95. Fukuda T, et al. Delayed maturation of neuronal architecture and synaptogenesis in cerebral cortex of Mecp2-deficient mice. J Neuropathol Exp Neurol. 2005;64:537-44.

96. Sadakata T, et al. Autistic-like phenotypes in Cadps2-knockout mice and aberrant CADPS2 splicing in autistic patients. J Clin Invest. 2007;117:931-42.

97. Powell E, et al. Genetic disruption of cortical interneuron development causes region and GABA cell type specific deficits, epilepsy, and behavioral dysfunction. J Neurosci. 2003;23:62231.

98. Meyer U, et al. Adult brain and behavioral pathological markers of prenatal immune challenge during early/middle and late fetal development in mice. Brain, Behav Immun. 2007;22:469-86.

99. Gant JC, et al. Decreased number of interneurons and increased seizures in neuropilin 2 deficient mice: Implications for autism and epilepsy. Epilepsia 2009; in press.

100. Tripathi $P$, et al. Increased susceptibility to kainic acid-induced seizures in Engrailed-2 knockout mice. Neuroscience. 2009;159:842-9. 